\title{
Training of children and adolescents' mental health nursing for nursing students in Japan
}

\author{
Akiko Funakoshi ${ }^{* 1}$, Aki Tsunoda ${ }^{2}$, Yuki Hada ${ }^{3}$ \\ ${ }^{1}$ College of Nursing Art and Science, University of Hyogo, Akashi, Japan \\ ${ }^{2}$ College of Nursing, St. Luke's International University, Tokyo, Japan \\ ${ }^{3}$ Nursing Sciences, Nihon Fukushi University, Tokai, Japan
}

Received: February 19, 2017

DOI: $10.5430 /$ jnep.v7n9p34
Accepted: March 10, 2017

URL: https://doi.org/10.5430/jnep.v7n9p34

Online Published: April 5, 2017

\begin{abstract}
Background: Children and adolescents' mental health nursing has not been positioned in the curriculum of nursing schools in Japan. The purpose of the present study is to clarify the prevalence of training of children and adolescents' mental health nursing for nursing students.

Methods: A cross-sectional study was conducted from September to October 2013 in Japan. Faculties of pediatric and psychiatric nursing both reported on the educational contents and methods of children and adolescents' mental health nursing by selfadministered questionnaires. To compare prevalence of the training of children and adolescents' mental health nursing between pediatric and psychiatric nursing, chi-square tests were carried out.

Results: The participants in the study were 133 pediatric (39.8\%) and 123 psychiatric nursing departments (36.8\%). Over $80 \%$ of participants had instructed the following 4 educational contents: process of mental development, mental health issues surrounding children and adolescents, related laws and regulations, and classification and treatment for children and adolescents with mental illnesses. Whereas, less than $40 \%$ of them had instructed the other 3 contents: nursing care for children and adolescents with mental illnesses, support agency for children and adolescents, and family support. Pediatric nursing had significantly higher prevalence than psychiatric nursing among process of mental development, mental health issues surrounding children and adolescents, and related laws and regulations.

Conclusions: Japanese nursing schools have dealt with basic knowledge of mental health with children and adolescents. It will be a challenges in the future to enhance training of practical nursing.
\end{abstract}

Key Words: Mental health nursing, Children and adolescents, Nursing students

\section{INTRODUCTION}

The mental health of children and adolescents is a crucial issue faced by many countries, and it is also intimately connected to social problems such as juvenile crime, child abuse and suicide. In fact, mental disorders affect $10 \%-20 \%$ of children and adolescents worldwide. ${ }^{[1]}$ A current global epidemiological data consistently reports that up to $20 \%$ of children and adolescents suffer from mental illnesses, and suicide is the third leading cause of death among children and adolescents, and up to $50 \%$ of all adult mental disorders have their onset in adolescence. ${ }^{[2]}$ Conway, et al. ${ }^{[3]}$ clarified that adolescents with prior lifetime mental disorders had high rates of both alcohol (10.3\%) and illicit drug abuse (14.9\%). There have been increasing opportunities for children and

${ }^{*}$ Correspondence: Akiko Funakoshi; Email: akiko_funakoshi@cnas.u-hyogo.ac.jp; Address: College of Nursing Art and Science, University of Hyogo, 13-71 Kitaoji-cho, Akashi, Hyogo, Japan. 
adolescents' mental health nursing. Nevertheless, nurses feel a lack of confidence and difficulties in caring for children and adolescents with mental health problems and reported insufficient preparation to manage them. It is one of the reasons that children and adolescents' mental health nursing has not been positioned in the curriculum of nursing schools. Killeen ${ }^{[4]}$ indicated that as a profession, the guarantee that the child and adolescent psychiatric nurses possess the requisite skills to care for youth and families with a wide variety of actual or potential health problems has far-reaching implications for both graduate and undergraduate programs. It is necessary for school to provide an efficient educational programs of children and adolescents' mental health nursing for nursing students.

\subsection{Mental health care for children and adolescents in Japan}

The mental health of children and adolescents is also an important issue in Japan. According to the results of a survey of patients released by the Ministry of Health, Labour and Welfare, ${ }^{[5]}$ there are more than 226,000 patients under 20 years of age who suffer from mental disorders in Japan, and that number has increased 1.9-fold in the last decade. The promotion of children's mental health is a high priority policy issue in the Japanese government.

The Japanese government has developed comprehensive children and adolescents' mental health services covering a wide range of care from primary care to specialized care since 2011 as national policy (Project of Network of Care for Children and Adolescents' Mental Health, 2011). The local prefectural governments have established their base hospitals of care for children and adolescents' mental health which provide mental health care in cooperation with relevant organizations - other hospitals, health clinics, referral centers for children's welfare, community health centers, educational institutions, and police stations. The development of such a comprehensive approach has expanded opportunities for nurses to provide care for children and adolescents with mental illnesses.

\subsection{Nurses' difficulties in caring for children and adoles- cents with mental health problems}

Nurses who encountered children and adolescents with mental health problems have experienced difficulties. Ramritu et al. ${ }^{[6]}$ reported from a survey in Australia that $90 \%$ of nurses in a general hospital setting encountered problems in caring for adolescents with mental health problems and only $41 \%$ of them were satisfied with their ability to provide care. Watson $^{[7]}$ also reported that $79 \%$ of nurses in a children's hospital stated they did not feel experienced in meeting the

Published by Sciedu Press needs of young people with mental health problems from a study conducted in the UK. In addition, Sato et al. ${ }^{[8]}$ indicated that nearly $60 \%$ of nurses who have experienced care for children in various inpatient settings stated a need for consultation in mental care.

In particularly, in specialized inpatient settings nurses face difficulties in caring for children and adolescents with mental disorders. More than $80 \%$ of nurses working in psychiatric inpatient care for children and adolescents have been involved in episodes of physical aggression and many of them felt emotional and professional sequelae linked to attending work. ${ }^{[9]}$ Our previous research clarifies that Japanese nurses in inpatient settings have many kinds of difficulties and common ones are dealing with aggressive behavior, building therapeutic relationships and finding the underlining problem. ${ }^{[10]}$ Hosokawa ${ }^{[11]}$ reported that novice nurses who were first assigned to children and adolescents' psychiatric units were heavily impacted by the particularity in care. Nurses play important roles in psychiatric inpatient care for children and adolescents, and their care can affect every facet of the patients' daily lives. Nurses while working with young psychotic patients deal with a great variety of symptoms and problems in their clinical practice. ${ }^{[12]}$

Nurses are in need of more education about mental health care for children and adolescents. Nursing staff working in the pediatric unit of a general hospital reported feeling unprepared to manage children with complex emotional and psychological issues and feeling inadequately skilled and knowledgeable to protect the safety of the children. ${ }^{[13]}$ Watson $^{[7]}$ indicated that $88 \%$ of nurses felt training in mental health issues was needed for all nurses in pediatric settings.

\subsection{Educational trial of children and adolescents' men- tal health nursing}

Children and adolescents' mental health nursing has not been positioned in the curriculum of nursing schools but there are several educational trials; interactive workshops including role play with professionals of children and adolescents' mental health services ${ }^{[14,15]}$ and placement in a clinical setting of children and adolescents' mental health services. ${ }^{[16]}$ Richardson ${ }^{[16]}$ stated that the most obvious benefits of the placements were the opportunities to observe different ways of interacting with children and adolescents with mental health problems and of the modelling provided by professionals.

In Japan, nursing students are comprehensively provided fundamental education required to be a general nurse without specialization and subdivision in a 3- or 4-year course, and they can be registered nurses only by passing the national 
examination after graduation. There are only few case examples of education about mental health care for children and adolescents in Japan, ${ }^{[17,18]}$ and the implementation of training of children and adolescents' mental health nursing for nursing students on a nationwide scale is not clear.

\subsection{Aim of the study}

The purpose of the present study is to clarify the prevalence of training of children and adolescents' mental health nursing for nursing students. It is necessary to get a clear picture of the training of children and adolescents' mental health nursing in order to develop an effective training program. Children and adolescents mental health is a specialty that can fall between children's and mental health nursing, with neither specialty including a significant amount of teaching on the subject in their undergraduate programs (Lowe \& Campbell, 2014). To illustrate educational role-sharing between pediatric and psychiatric nursing, both of which are strongly correlated with mental health for children and adolescents, can be valuable evidence for exploring the nursing education based on the prospects for the future.

\section{Methods}

In the present study children and adolescents were defined as people under the age 18. A quantitative descriptive crosssectional study was conducted in the present study.

\subsection{Participants}

Participants of the present study were faculties of pediatric and psychiatric nursing who work in nursing schools authorized by Ministry of the Health, Labour and Welfare in Japan. We surveyed 334 nursing schools which were 238 senior and junior colleges across-the-country and 96 professional schools in the Tokai-Hokuriku region. The region consists of the seven prefectures located in the center of Japan which include both urban and rural areas.

\subsection{Data collection}

Chiefs of pediatric and psychiatric nursing were both requested to complete the self-administered questionnaires on behalf of their respective departments in their schools and mail them to the university researcher. The data collection was conducted from September to October 2013.

Concerning children and adolescents' mental health nursing, the educational contents and methods, faculties' experiences in a clinical setting, and the recognition of the necessity to education were elicited by the questionnaires. We extracted the following seven categories as educational content relative to children and adolescents' mental health nursing by reviewing textbooks of both pediatric and psychiatric nursing in Japan: process of mental development, mental health issues surrounding children and adolescents, related laws and regulations, classification and treatment of children and adolescents with mental illnesses, nursing care for children and adolescents with mental illnesses, support agency for children and adolescents, and family support. To uncover further details, more concrete educational content was extracted as sub-categories in the first four respective categories. The participants selected if these seven categories and the subcategories were to be incorporated into this year's curriculum or not, and gave detailed descriptions of all categories of children and adolescents' mental health nursing which they teach. They also answered which style was adopted in these classes among lectures, school practices, and clinical practices.

The participants answered how many faculty members in their department have experience in caring for children and adolescents with mental illnesses or working at a specialized unit. Their recognition of the necessity for education was assessed with an answer to the question "Is it necessary to enhance the training of children and adolescents' mental health nursing for nursing students?". The answers were chosen from 'strongly agree' to 'strongly disagree'.

\subsection{Data analysis}

To compare prevalence of the training of children and adolescents' mental health nursing between pediatric and psychiatric nursing, chi-square tests were carried out. All data analyses were performed using IBM SPSS Statistics 23 for Windows (IBM Corp. Released 2015).

\subsection{Ethical considerations}

All participants were informed in writing about the study purpose and methods. They were assured that neither they nor their places of work would be identified. They were also informed that participation in the study was voluntary and that they could terminate at any time if they were unhappy with any aspect. Consent from participants was confirmed by their filling out the questionnaires. The Ethics Committee of the university approved the research protocol before starting the study and that it conforms to the provisions of the Declaration of Helsinki.

\section{RESULTS}

A total of 256 out of 668 departments to which the questionnaires were distributed to responded (response rate $=$ $38.3 \%$ ). The sample consisted of 133 pediatric nursing departments (response rate $=39.8 \%$ ) and 123 psychiatric nursing departments (response rate $=36.8 \%$ ): $157(61.3 \%$ ) of the departments were colleges and 99 (38.4\%) of them were professional schools. The medians and modes of the number of faculty members where colleges had 3 and pro- 
fessional schools had 1 in each respective department. Table 1 shows the number of faculty members who had experience in children and adolescents' mental health nursing in both departments. More than $20 \%$ of departments didn't have any faculty members who had experience working at a specialized unit, and more than $40 \%$ didn't have any faculty members who had experience in caring for children and adolescents with mental illnesses. Psychiatric nursing had a significantly higher percentage of faculty members with experience in children and adolescents' mental health nursing than pediatric nursing.

There were 122 (91.7\%) pediatric nursing departments and 111 (90.2\%) psychiatric nursing departments who responded that at least one of the seven categories was included as educational content relative to children and adolescents' mental health nursing. It didn't show a significant difference between pediatric nursing departments and psychiatric nursing departments.

The prevalence of the 7 educational categories of children and adolescents' mental health nursing is illustrated in Ta- ble 2. The 4 categories: Process of Mental Development, Mental Health Issues Surrounding Children and Adolescents, Related Laws and Regulations, and Classification and Treatment of Children and Adolescents with Mental Illnesses, were dealt with by more than $80 \%$ of departments, respectively. Meanwhile, the remaining 3 categories were dealt with by less than $40 \%$ of them.

Table 3 shows sub-categories of the 4 main categories. Firstly, in Process of Mental Development, 4 of 5 subcategories had significant differences between pediatric and psychiatric nursing. Piaget's Stage of Cognitive Development and Bowlby's Attachment Theory had significant higher prevalence in pediatric nursing departments than psychiatric nursing departments. Whereas, Freud's Stage of Psychosexual Development had significantly lower prevalence in pediatric nursing departments than psychiatric nursing departments. Erickson's Stage of Psychosocial Theory was dealt with by more than $80 \%$ of departments in both pediatric and psychiatric nursing, although Mahler's Separation-Individuation Theory was dealt with by less than $40 \%$ of departments.

Table 1. Assignment of faculties with experience of children and adolescents' mental health nursing

\begin{tabular}{|c|c|c|c|c|c|c|c|c|}
\hline & \multicolumn{2}{|c|}{$\begin{array}{l}\text { Total } \\
(\mathrm{N}=\mathbf{2 5 6})\end{array}$} & \multicolumn{2}{|c|}{$\begin{array}{l}\text { Pediatric nursing } \\
(\mathrm{n}=133)\end{array}$} & \multicolumn{2}{|c|}{$\begin{array}{l}\text { Psychiatric nursing } \\
(\mathrm{n}=123)\end{array}$} & \multirow[t]{2}{*}{$\chi^{2}$} & \multirow{2}{*}{$p$} \\
\hline & $\mathbf{n}$ & $\%$ & $\mathbf{n}$ & $\%$ & $\mathbf{n}$ & $\%$ & & \\
\hline Working at a specialized unit & 51 & 19.9 & 16 & 12.0 & 35 & 28.5 & 10.80 & $.001 * *$ \\
\hline $\begin{array}{l}\text { Care for children and adolescent } \\
\text { with mental illnesses }\end{array}$ & 146 & 57.0 & 67 & 50.4 & 79 & 64.2 & 5.00 & $.017^{*}$ \\
\hline
\end{tabular}

Table 2. Prevalence of the 7 categories of children and adolescents' mental health nursing between pediatric and psychiatric nursing

\begin{tabular}{|c|c|c|c|c|c|c|c|c|}
\hline & \multicolumn{2}{|c|}{$\begin{array}{l}\text { Total } \\
(\mathrm{N}=\mathbf{2 5 6})\end{array}$} & \multicolumn{2}{|c|}{$\begin{array}{l}\text { Pediatric nursing } \\
(n=133)\end{array}$} & \multicolumn{2}{|c|}{$\begin{array}{l}\text { Psychiatric nursing } \\
(\mathrm{n}=123)\end{array}$} & \multirow[t]{2}{*}{$\chi^{2}$} & \multirow[t]{2}{*}{$p$} \\
\hline & $\mathbf{n}$ & $\%$ & $\mathbf{n}$ & $\%$ & $\mathbf{n}$ & $\%$ & & \\
\hline Process of Mental Development & 244 & 95.3 & 131 & 98.5 & 113 & 91.9 & 6.28 & $.012 *$ \\
\hline $\begin{array}{l}\text { Mental Health Issues Surrounding Children } \\
\text { and Adolescents }\end{array}$ & 237 & 92.6 & 129 & 97.0 & 108 & 87.8 & 7.85 & $.005 * *$ \\
\hline Related Laws and Regulations & 233 & 91.0 & 133 & 100.0 & 100 & 81.3 & 26.25 & $<.001 * *$ \\
\hline Classification and Treatment & 206 & 80.5 & 105 & 78.9 & 101 & 82.1 & 0.41 & .316 \\
\hline $\begin{array}{l}\text { Nursing Care for Children and Adolescents } \\
\text { with Mental Illnesses }\end{array}$ & 82 & 32.0 & 38 & 28.6 & 44 & 35.8 & 1.52 & .136 \\
\hline Support Agency for Children and Adolescents & 108 & 42.2 & 63 & 47.4 & 45 & 36.6 & 3.05 & .053 \\
\hline Family Support & 81 & 31.6 & 38 & 28.6 & 43 & 35.0 & 1.12 & .178 \\
\hline
\end{tabular}

$\chi^{2}$ test, ${ }^{*} p<.05,{ }^{* *} p<.01$.

Secondly, in Mental Health Issues Surrounding Children and Adolescents, all subcategories had significant differences between pediatric and psychiatric nursing. Child abuse alone had higher prevalence in pediatric nursing departments than psychiatric nursing, while all others had lower prevalence in pediatric nursing departments than psychiatric nursing. 
Misdemeanor was dealt by less than $40 \%$ of departments.

Thirdly, in Related Laws and Regulations, Child Welfare Act and Child Abuse Prevention Act had significantly higher prevalence in pediatric nursing departments than psychiatric nursing departments. Whereas, Mental Health Act had significantly lower prevalence in pediatric nursing departments than psychiatric nursing departments. Juvenile Act was dealt with by less than $20 \%$ in both departments.

Table 3. Prevalence of the 4 subcategories of children and adolescents' mental health nursing between pediatric and psychiatric nursing

\begin{tabular}{|c|c|c|c|c|c|c|c|c|}
\hline & \multicolumn{2}{|c|}{$\begin{array}{l}\text { Total } \\
(\mathrm{N}=256)\end{array}$} & \multicolumn{2}{|c|}{$\begin{array}{l}\text { Pediatric nursing } \\
(\mathrm{n}=133)\end{array}$} & \multicolumn{2}{|c|}{$\begin{array}{l}\text { Psychiatric nursing } \\
(\mathrm{n}=123)\end{array}$} & \multirow[t]{2}{*}{$\chi^{2}$} & \multirow{2}{*}{$p$} \\
\hline & $\mathbf{n}$ & $\%$ & $\mathbf{n}$ & $\%$ & $\mathbf{n}$ & $\%$ & & \\
\hline \multicolumn{9}{|l|}{ Process of Mental Development } \\
\hline Freud's Stage of Psychosexual Development & 146 & 57.0 & 45 & 33.8 & 101 & 82.1 & 60.78 & $<.001^{* *}$ \\
\hline Erickson's Stage of Psychosocial Development & 226 & 88.3 & 124 & 93.2 & 102 & 82.9 & 6.56 & $.009^{* *}$ \\
\hline Piaget's Stages of Cognitive Development & 169 & 66.0 & 125 & 94.0 & 44 & 35.8 & 96.55 & $<.001^{* *}$ \\
\hline Mahler's Separation-Individuation Theory & 95 & 37.1 & 50 & 37.6 & 45 & 36.6 & 0.03 & .485 \\
\hline Bowlby's Attachment Theory & 166 & 64.8 & 112 & 84.2 & 54 & 43.9 & 45.54 & $<.001^{* *}$ \\
\hline \multicolumn{9}{|c|}{ Mental Health Issues Surrounding Children and Adolescents } \\
\hline School Refusal and Social Withdrawal & 168 & 65.6 & 77 & 57.9 & 91 & 74.0 & 7.33 & $.005 * *$ \\
\hline Domestic Violence & 94 & 36.7 & 31 & 23.3 & 63 & 51.2 & 21.43 & $<.001 * *$ \\
\hline Suicide and Self-Injury & 119 & 46.5 & 41 & 30.8 & 78 & 63.4 & 27.28 & $<.001^{* *}$ \\
\hline Misdemeanor & 80 & 31.3 & 33 & 24.8 & 47 & 38.2 & 5.34 & $.015^{*}$ \\
\hline Child Abuse & 204 & 79.7 & 126 & 94.7 & 78 & 63.4 & 38.73 & $<.001^{* *}$ \\
\hline \multicolumn{9}{|l|}{ Related Laws and Regulations } \\
\hline Child Welfare Act & 153 & 59.8 & 126 & 94.7 & 27 & 22.0 & 140.79 & $<.001 * *$ \\
\hline Child Abuse Prevention Act & 196 & 76.6 & 127 & 95.5 & 69 & 56.1 & 55.26 & $<.001 * *$ \\
\hline $\begin{array}{l}\text { Act on Support for Persons with Development } \\
\text { Disabilities }\end{array}$ & 135 & 52.7 & 83 & 62.4 & 52 & 42.3 & 10.39 & $.001 * *$ \\
\hline Mental Health Act & 116 & 45.3 & 26 & 19.5 & 90 & 73.2 & 74.15 & $<.001 * *$ \\
\hline Juvenile Act & 38 & 14.8 & 23 & 17.3 & 15 & 12.2 & 1.31 & .166 \\
\hline \multicolumn{9}{|l|}{ Classification and Treatment } \\
\hline Mental Retardation & 138 & 53.9 & 65 & 48.9 & 73 & 59.3 & 2.82 & .060 \\
\hline Pervasive Development Disorder & 173 & 67.6 & 89 & 66.9 & 84 & 68.3 & 0.06 & .460 \\
\hline Hyperkinetic Disorder & 157 & 61.3 & 83 & 62.4 & 74 & 60.2 & 0.14 & .405 \\
\hline Learning Disorder & 150 & 58.6 & 80 & 60.2 & 70 & 56.9 & 0.28 & .345 \\
\hline Tic Disorder & 79 & 30.9 & 32 & 24.1 & 47 & 38.2 & 6.00 & $.010 *$ \\
\hline Separation Anxiety Disorder & 74 & 28.9 & 30 & 22.6 & 44 & 35.8 & 5.43 & $.014 *$ \\
\hline Early-onset Schizophrenia & 53 & 20.7 & 6 & 4.5 & 47 & 38.2 & 44.21 & $<.001^{* *}$ \\
\hline Early-onset Mood Disorder & 38 & 14.8 & 6 & 4.5 & 32 & 26.0 & 23.38 & $<.001 * *$ \\
\hline Early-onset Eating Disorder & 108 & 42.2 & 43 & 32.3 & 65 & 52.8 & 11.03 & $.001 * *$ \\
\hline Early-onset Anxiety Disorder & 44 & 17.2 & 10 & 7.5 & 34 & 27.6 & 18.18 & $<.001 * *$ \\
\hline Early-onset Personality Disorder & 56 & 21.9 & 12 & 9.0 & 44 & 35.8 & 26.76 & $<.001^{* *}$ \\
\hline Early-onset somatoform disorder & 32 & 12.5 & 6 & 4.5 & 26 & 21.1 & 16.15 & $<.001 * *$ \\
\hline
\end{tabular}

$\chi^{2}$ test, ${ }^{*} p<.05,{ }^{* *} p<.01$.

Lastly, in Classification and Treatment, the following 4 disorders: Mental Retardation, Pervasive Development Disorder, Hyperkinetic Disorder, and Learning Disorder didn't have significant differences between pediatric and psychiatric nursing departments which were dealt with by more than $50 \%$ in both departments. The remaining 8 disorders had a significantly higher prevalence in psychiatric nursing departments than in pediatric nursing departments, and 5 of them were dealt with by less than $10 \%$ of pediatric nursing departments.

The style of class for the training of children and adolescents' mental health nursing is illustrated in Table 4. A hands-on style at schools and clinical settings was adopted in the teaching of the 7 educational categories by approximately $40 \%$ 
of both departments, while a lecture style was adopted by $90 \%$ of them. The style of class for the training of children and adolescents' mental health nursing didn't have significant differences between pediatric nursing departments and psychiatric nursing departments.

Table 5 shows the recognition of the necessity for educa- tion of departments. Almost $90 \%$ of departments answered 'strongly agree' or 'agree' to the question "Is it necessary to enhance the training of children and adolescents' mental health nursing for nursing students?", and there was not a significant difference between pediatric nursing departments and psychiatric nursing departments.

Table 4. Style of class for the training of children and adolescents' mental health nursing

\begin{tabular}{|c|c|c|c|c|c|c|c|c|}
\hline & \multicolumn{2}{|c|}{$\begin{array}{l}\text { Total } \\
(\mathrm{N}=256)\end{array}$} & \multicolumn{2}{|c|}{$\begin{array}{l}\text { Pediatric nursing } \\
(\mathrm{n}=133)\end{array}$} & \multicolumn{2}{|c|}{$\begin{array}{l}\text { Psychiatric nursing } \\
(\mathrm{n}=123)\end{array}$} & \multirow[t]{2}{*}{$\chi^{2}$} & \multirow[t]{2}{*}{$p$} \\
\hline & $\mathbf{n}$ & $\%$ & $\mathbf{n}$ & $\%$ & $\mathbf{n}$ & $\%$ & & \\
\hline Lecture & 233 & 91.0 & 122 & 91.7 & 111 & 90.2 & 0.17 & .421 \\
\hline School practice & 104 & 40.6 & 58 & 43.6 & 46 & 37.4 & 1.02 & .189 \\
\hline Clinical practice & 105 & 41.0 & 56 & 42.1 & 49 & 39.8 & 0.14 & .405 \\
\hline
\end{tabular}

Table 5. The necessity to enhance the training of children and adolescents' mental health nursing for nursing students

\begin{tabular}{|c|c|c|c|c|c|c|c|c|}
\hline & \multicolumn{2}{|c|}{$\begin{array}{l}\text { Total } \\
(\mathrm{N}=\mathbf{2 5 6})\end{array}$} & \multicolumn{2}{|c|}{$\begin{array}{l}\text { Pediatric nursing } \\
(n=133)\end{array}$} & \multicolumn{2}{|c|}{$\begin{array}{l}\text { Psychiatric nursing } \\
(\mathrm{n}=123)\end{array}$} & \multirow[t]{2}{*}{$\chi^{2}$} & \multirow[t]{2}{*}{$p$} \\
\hline & $\mathbf{n}$ & $\%$ & $\mathbf{n}$ & $\%$ & $\mathbf{n}$ & $\%$ & & \\
\hline Strongly agree & 121 & 48.8 & 69 & 53.5 & 52 & 43.7 & 6.86 & .076 \\
\hline Agree & 105 & 41.0 & 53 & 39.8 & 52 & 42.3 & & \\
\hline Disagree & 21 & 8.2 & 6 & 4.5 & 15 & 12.2 & & \\
\hline Strongly disagree & 1 & 0.4 & 1 & 0.8 & 0 & 0.0 & & \\
\hline
\end{tabular}

\section{Discussion}

It was revealed that practical educational contents have a low prevalence, despite fundamental knowledge having a high prevalence, in training of children and adolescents' mental health nursing for nursing students. In the results of the present study, the 3 categories: nursing care for children and adolescents with mental illnesses, support agency for children and adolescents, and family support, were dealt with by less than $50 \%$ of pediatric nursing departments and psychiatric nursing departments. These three educational contents should be designed to teaching practical expertise in how nurses provide care for children and adolescents with mental problems and their families. Meanwhile, in the present study, almost $90 \%$ of departments considered it necessary to enhance the training of children and adolescents' mental health nursing for nursing students. According to adolescents who received mental health care and their parents, they had a low satisfaction level with their care about detailed information of each treatment intervention. ${ }^{[19]}$ This evidence implies the importance of enhancement in practical education.

The low prevalence of practical educational contents is considered to be causally related to few faculty members with experience of working in specialized clinical settings, difficulties to secure suitable training facilities, and inflexible

Published by Sciedu Press and unadaptable curriculum. Riedford ${ }^{[20]}$ reported that decreasing inpatients and number of days of hospitalization has made it difficult to provide quality clinical experiences for undergraduate nursing students, particularly in specialty areas such as mental health. Tratnack et al. ${ }^{[21]}$ also stated nursing education is becoming increasingly focused on didactic lectures and technical skill attainment, with a decrease in psychiatric content. Nursing schools need to develop educational resources and improve their curriculum for nursing students to learn practical expertise in children and adolescents' mental health nursing.

When comparing the educational contents of children and adolescents' mental health nursing in pediatric nursing departments and psychiatric nursing departments, there are significant differences in the prevalence of the subcategories rather than the 7 categories. This result shows training from a specialized perspective of each department can provide various educational contents of children and adolescents' mental health nursing. Children and adolescents' mental health nursing is cross-disciplinary which is associated with maternal nursing, community health nursing, home care nursing, and family nursing, and which is included as a training course for midwives, public health nurses, and school nurses. There are some reports of experimental efforts to promote training 
of practical ability for nursing students in cooperation with different specialized faculties of nursing schools. ${ }^{[22,23]}$

In addition to the cooperation among faculties, it is reportedly beneficial for enhancement in practical education to involve youth who have experienced mental health problems and their families deeply, to collaborate with professionals of children and adolescents mental health services, and to use audiovisual materials. Nursing students could acquire the ability to think critically about mental health issues and the collaborative skills through partnerships among faculties, professionals of mental health agencies, and community partners. ${ }^{[20,24]}$ Dearing \& Steadman ${ }^{[25]}$ reported that voice simulation exercise using audiotaped presentation could help nursing students decrease stigma and enhance the ability to develop therapeutic relationships. McGarry et al. ${ }^{[26]}$ recommended to adapt simulation education to prepare for practicum in clinical settings of children and adolescents' mental health. It is needed to improve educational methods.

The present study clarified the whole picture of the training of children and adolescents' mental health nursing in Japan for the first time with data on the prevalence of training from pediatric nursing departments and psychiatric nursing departments. It revealed that children and adolescents' mental health nursing can fall among other specialties in Japanese nursing schools and be taught more comprehensively. However there are the following limitations. First, we couldn't get detailed information such as hours of training, ratio of faculties to students, and educational outcomes. Especially, the present study doesn't indicate contents of nursing care. The previous studies suggest that the process of child and adolescent psychiatric nursing incudes assessing the relationship patient acuity and environment, relieving difficulties, collaborating with other professions, and building the therapeutic relationship. ${ }^{[27-29]}$ Next, qualitative description on how to teach also was not investigated. Lastly, we couldn't identify the features of each nursing school in individual situations.

\section{Conclusion}

Japanese nursing schools have dealt with basic knowledge rather than practical expertise of mental health with children and adolescents. It will be a challenge in the future to enhance training of practical nursing. Further studies must clarify attainment targets, methods, and outcomes of children and adolescent' mental health nursing by analysis of education examples and intervention study in order to develop an effective practical training program.

\section{ACKNOWLEDGEMENTS}

I would like to thank participants in this study. This study was supported in part by Grants-in-Aid for Scientific Research (No. JP25463569) from Japan Society for the Promotion of Science. No conflict of interest has been declared by the authors.

\section{CONFlicts OF InTEREST Disclosure}

The authors declare that there is no conflict of interest.

\section{REFERENCES}

[1] Kieling C, Baker-Henningham H, Belfer M, et al. A Child and adolescent mental health worldwide: evidence for action. Lancet 2011; 378: 1515-1525. http://dx.doi.org/10.1016/S0140-6 736 (11) 60827-1

[2] Belfer ML. Child and adolescent mental disorders: the magnitude of the problem across the globe. Journal of Child Psychology and Psychiatry. 2008; 49(3): 226-236. http://dx.doi.org/10.1111 /j.1469-7610.2007.01855.x

[3] Conway KP, Swendsen J, Husky MM, et al. Association of Lifetime Mental Disorders and Subsequent Alcohol and Illicit Drug Use: Results From the National Comorbidity Survey-Adolescent Supplement Journal of the American Academy of Child \& Adolescent Psychiatry. 2016; 55(4): 280-288. http://dx.doi.org/10.1016/j.jaa c. 2016.01 .006

[4] Killeen MR. Challenges and choices in child and adolescent mental health-psychiatric nursing. Journal of Child \& Adolescent Psychiatric \& Mental Health Nursing. 1990; 3(4): 113-119. http: //dx.doi.org/10.1111/j.1744-6171.1990.tb00457.x

[5] Ministry of Health, Labour and Welfare in Japan. Patient survey. 2014; [ted 2017 Feb 13]. Available from: http://www.mhlw.go. jp/toukei/saikin/hw/kanja/14/
[6] Ramritu P, Courtney M, Stanley T, et al. Experiences of the generalist nurse caring for adolescents with mental health problems. Journal of Child Health Care. 2002; 6(4): 229-244. http://dx.doi.org/10. $1177 / 136749350200600401$

[7] Watson E. CAMHS liaison: supporting care in general paediatric settings. Pediatric Nursing. 2006; 18(1): 30-33. http://dx.doi.o $\mathrm{rg} / 10.7748 /$ paed2006.02.18.1.30.c1018

[8] Sato Y, Shiwaku H, Endo Y, et al. Study on nurses' awareness of the need for psychological care for children. Journal of North Japan Academy of Nursing Science. 2011; 13(2): 17-23. (in Japanese)

[9] Dean AJ, Gibbon P, McDermott BM, et al. Exposure to aggression and the impact on staff in a child and adolescent inpatient unit. Archives of Psychiatric Nursing. 2010; 24(1): 15-26. http: //dx.doi.org/10.1016/j. apnu. 2009.01.002

[10] Funakoshi A. Difficulties of Children and adolescents Psychiatric Nursing. Seishin-Kango. 2013; 16(4): 57-64. (in Japanese)

[11] Hosokawa M. Meanings of experiences to nurse to children who hospitalized in child psychiatry department: by new graduate nurses narrative. Reports of Nursing Research, Nursing Teacher's Course of Center Professional Education, Kanagawa University of Human Services. 2011; 36: 162-169. (in Japanese) 
[12] Lesinskiene S, Jegorova N, Ranceva N. Nursing of young psychotic patients: analysis of work environments and attitudes. Journal of Psychiatric and Mental Health Nursing. 2007; 4(8): 758-764. http://dx.doi.org/10.1111/j.1365-2850.2007.01187.x

[13] Reid-Searl K, Dwyer T, Happell B, et al. Caring for children with complex emotional and psychological disorders: experiences of nurses in a rural paediatric unit. Journal of Clinical Nursing. 2009; 18(24): 3441-3449. http://dx.doi .org/10.1111/j.1365-270 $2.2008 .02567 . \mathrm{x}$

[14] Lowe L, Campbell A. Evaluation of a study day on child and adolescent mental health services. Mental Health Practice. 2014; 17(5): 19-24. http://dx.doi.org/10.7748/mhp2014.02.17 .5 .19 .8826

[15] Terry J, Maunder EZ, Bowler N, et al. Inter-branch initiative to improve children's mental health. British Journal of Nursing. 2009; 18(5): 282-287. http://dx.doi.org/10.12968/bjon.2009.18 .5 .40540

[16] Richardson BP. Child and Adolescent Mental Health Service (CAMHS) placements for pre-registration child branch nursing students: potential benefits. Nurse Education Today. 2011; 31(5): 494498. http://dx.doi.org/10.1016/j.nedt. 2010.08.007

[17] Goto M. Clinical practice for nursing students at a children' psychiatric ward. Nursing Education. 2002; 3(3): 98-107. (in Japanese)

[18] Iwase J, Kitayama Y, Nakai Y, et al. Support for mental development at handicapped children's facilities. The 45th Japanese Nursing Society - Psychiatric Nursing. 2015; 45: 278-281. (in Japanese)

[19] Tas FV, Guvenir T, Cevrim E. Patients' and their parents' satisfaction levels about the treatment in a child and adolescent mental health inpatient unit. Journal of Psychiatric and Mental Health Nursing. 2010; 17(9): 769-74. http://dx.doi.org/10.1111/j.1365-2 $850.2010 .01612 . \mathrm{x}$

[20] Riedford KB. Bridging the gap between clinical experience and client access: community engagement. Journal of Nursing Education. 2011; 50(6): 337-40. http://dx.doi .org/10.3928/01484 834-20110415-05
[21] Tratnack SA, O'Neill CM, Graham P. Immersion Experience in Undergraduate Psychiatric Mental Health Nursing. Journal of Nursing Education. 2011; 50(9): 532-535. http://dx.doi.org/10.3928 101484834-20110531-02

[22] Nishiyama C, Hashimoto T, Toshima S, et al. The production of Nursing Skill Matrix in the Basic Course on Nursing Education. Journal of Shoken Gakuen Gunma University of Health and Welfare. 2013; 2: 63-68. (in Japanese)

[23] Williams-Barnard C, Sweatt A, Harkness G, et al. The clinical home community: a model for community-based education. International Nursing Review. 2004; 51(2): 104. http://dx.doi.org/10.11 $11 / j .1466-7657.2003 .00215 . x$

[24] Scott S. A TRIPARTITE LEARNING PARTNERSHIP IN HEALTH PROMOTION. Nursing Praxis In New Zealand. 2011; 27(2): 16-23. PMid:21957557

[25] Dearing K, Steadman S. Challenging stereotyping and bias: a voice simulation study. Journal of Nursing Education. 2008; 47(2): 59-65. http://dx.doi.org/10.3928/01484834-20080201-07

[26] McGarry D, Cashin A, Fowler C. "Coming ready or not" high fidelity human patient simulation in child and adolescent psychiatric nursing education: diffusion of Innovation. Nurse Education Today. 2011; 31(7): 655-659. http://dx.doi.org/10.1016/j.n edt. 2011.01.002

[27] Rasmussen P, Henderson AN, Muir-Cochrane E. An analysis of the work of child and adolescent mental health nurses in an inpatient unit in Australia. Journal of Psychiatric and Mental Health Nursing. 2012; 19(4): 374-7. http://dx.doi.org/10.1111/j.1365-2850.20 $12.01890 . \mathrm{x}$

[28] Funakoshi A, Tanaka A, Hattori K, et al. Child and Adolescent Psychiatric Inpatient Care Provided by Expert Nurses-Nursing Intervention to Solve Children's Problems. KANGO-KENKYU. 2013; 46 (55) : 504-517.

[29] Funakoshi A, Tanaka A, Hattori A, et al. Process of Building PatientNurse Relationships in Child And Adolescent Psychiatric Inpatient Care: A Grounded Theory Approach in Japan. Journal of Nursing \& Patient Care. 2016; 1(2). http://dx.doi.org/10.4172/jnpc. 1000106 